\title{
Determination of SIRT1 rs12778366, FGFR2 rs2981582, STAT3 rs744166, and RAGE rs1800625 Single Gene Polymorphisms in Patients with Laryngeal Squamous Cell Carcinoma
}

\author{
Virgilijus Uloza, ${ }^{1}$ Toma Tamauskaite, ${ }^{2}$ Alvita Vilkeviciute $\left(\mathbb{D},{ }^{3}\right.$ Agne Pasvenskaite, ${ }^{1}$ \\ Vykintas Liutkevicius $\mathbb{D}^{1},{ }^{1}$ and Rasa Liutkeviciene $\mathbb{D}^{3}$ \\ ${ }^{1}$ Department of Otolaryngology, Academy of Medicine, Lithuanian University of Health Sciences, Kaunas, Lithuania \\ ${ }^{2}$ Academy of Medicine, Lithuanian University of Health Sciences, Kaunas, Lithuania \\ ${ }^{3}$ Neuroscience Institute, Lithuanian University of Health Sciences, Kaunas, Lithuania \\ Correspondence should be addressed to Rasa Liutkeviciene; rliutkeviciene@gmail.com
}

Received 7 April 2019; Accepted 28 September 2019; Published 12 November 2019

Academic Editor: Massimiliano M. Corsi Romanelli

Copyright (C) 2019 Virgilijus Uloza et al. This is an open access article distributed under the Creative Commons Attribution License, which permits unrestricted use, distribution, and reproduction in any medium, provided the original work is properly cited.

\begin{abstract}
Purpose. To determine the frequency of the genotype of signal transducer and activator of transcription protein 3 (STAT3) rs744166, sirtuin (SIRT1) rs12778366, fibroblast growth factor (FGFR2) rs2981582, and advanced glycosylation end productspecific receptor (RAGE) rs1800625 gene polymorphisms in patients with laryngeal squamous cell carcinoma (LSCC). Methods. A total of 944 subjects were evaluated, which includes 144 patients with LSCC and 800 healthy controls. The genotyping of STAT3 rs744166, SIRT1 rs12778366, FGFR2 rs2981582, and RAGE rs1800625 was carried out using the RT-PCR. Results. The analysis of STAT3 rs744166, SIRT1 rs12778366, and FGFR2 rs2981582 gene polymorphisms did not reveal any differences in genotype distribution between the patients with LSCC and the control subjects. However, statistical analysis revealed that genotypes (AA, AG, and GG) of rs1800625 in RAGE gene were distributed statistically significantly differently between patients and controls $(61.1 \%, 30.6 \%$, and $23.6 \%$ vs. $72.5 \%, 25.8 \%$, and $1.8 \%$, respectively; $p<0.001)$. Additionally, statistical significance was observed in allele distribution between these two groups, i.e., allele $\mathrm{G}$ at rs 1800625 was more frequently observed in the patient group than in controls $(23.6 \%$ vs. $14.6 \%$; $p<0.001)$. Conclusion. RAGE rs 1800625 gene polymorphism may play a significant role in laryngeal squamous cell carcinoma development.
\end{abstract}

\section{Introduction}

The TNM classification for cancers of the head and neck includes tumors of the nasal cavities, paranasal sinuses, oral cavity and larynx, nasopharynx, oropharynx, and hypopharynx [1]. Laryngeal squamous cell carcinoma (LSCC) is one of the largest subgroups, which accounts for $30 \%-40 \%$ of all malignant tumors of the head and neck region [2,3]. According to the International Agency for Research on Cancer and European Cancer Observatory (ECO), the age-standardized incidence rate of LSCC in Europe is 4.4/100 000 [4]. There were reported 177422 new cases of LSCC and 94771 deaths from LSCC worldwide in 2018 [5]. Despite the improvements in surgical techniques, chemotherapy, and radiotherapy, the 5 -year survival rates remain less than $60 \%$ [4]. It is well known that LSCC is a complex disease, which is caused by many environmental and genetic factors. The environmental factors that are reported to be associated with the increased risk of LSCC include smoking, alcohol consumption, exposure to carcinogens in the work environment, nutrition, and viral infections with human papilloma virus (HPV) and Epstein-Barr virus (EBV) [6-11]. In the last years, increasing interest has been focused on the role of gene polymorphisms in cancer development and progression $[8,12,13]$.

STAT proteins are a family of cytoplasmic transcription factors, which play an important role in the signal transduction through cytokines, hormones, and growth factors. There are evidences that signal transducer and activator of transcription protein 3 (STAT3) is implicated in the development 
and progression of cancer and plays a role in inducing neoplastic transformation. STAT3 participates in a series of tumorigenic processes such as cell proliferation and survival, antiapoptosis, angiogenesis, immune evasion, and inflammation [14]. Moreover, STAT3 can be activated by a variety of ligands that respond to massive signals such as IL-6, TNF$\alpha$, and VEGF [15-17]. Aberrant expression and constitutive activation of STAT3 are involved in a broad range of human malignancies, including gastric, breast, prostate, and nonsmall-cell lung cancers $[15,16,18-21]$.

The sirtuins (SIRT) are a highly conserved family of NAD-dependent class III deacetylases that helps to regulate the lifespan of diverse organisms. Mammalian sirtuins consist of 7 members, SIRT1-SIRT7, and some of them, especially SIRT1, have been shown to play relevant roles in the regulation of aging and longevity or in the pathogenesis of age-related metabolic diseases [22-24]. Upregulation of SIRT1 has been reported in breast cancer [25], prostate cancer [26], acute myeloid leukemia [27], and primary colon cancer [28]. It is known that SIRT1 can act both as a tumor promoter and as a suppressor [29, 30]. The apparent opposed roles of SIRT1 seem contradictory, but the multiple functions of SIRT1 made this possible. SIRT1 can negatively regulate both tumor suppressors ( $\mathrm{p} 53, \mathrm{FOXO}$ ) and oncogenic protein (survivin, $\beta$-catenin, and NF- $\kappa \mathrm{B}$ ) multiple pathways. The role of SIRT1 in tumorigenesis might also depend on the temporal and spatial distribution of different SIRT1 upstream regulators and downstream targets [31].

The human fibroblast growth factor (FGF) and its receptor families consist of 22 structurally related FGFs and four high-affinity tyrosine kinase FGF receptors (FGFR1 to 4 ) that are important for a cell signaling process [32]. The formation of the FGF-FGFR complex activates the intracellular tyrosine kinase, which mediates signal transduction through the direct phosphorylation of adaptor proteins [32, 33]. These complex FGF signaling networks are crucial in the multiple cell biological activities, such as proliferation, differentiation, mitogenesis, migration, and apoptosis, and thus are implicated in tumorigenesis [32-35]. Fibroblast growth factor receptor 2 (FGFR2) belongs to the FGFR family of tyrosine kinase receptors and contributes to the process of tumorigenesis through cell growth, invasiveness, motility, and angiogenesis. It should also be noted that, if the cancer cells overexpress an FGFR and can stimulate the cancer cells, a paracrine loop should be created [32]. At the present a huge interest is focused on FGFR2 polymorphisms, as it may have important implications in breast and other cancer carcinogeneses [36-39].

The receptor for advanced glycosylation end products (RAGE) is referred as a pattern recognition receptor that controls the innate immunity and belongs to the immunoglobulin superfamily of cell surface molecules with a broad spectrum of ligand specificities [40]. These structurally distinct ligands include the prototype of high-mobility group family proteins, members of the S100/calgranulin protein family, extracellular matrix proteins, $\beta$-amyloid, phosphatidylserine, complement $\mathrm{C} 3 \mathrm{a}$, and some advanced glycation end products [41]. Through interacting with its diverse ligand families, RAGE orchestrates many intracellular signal- ing pathways to control a variety of cellular processes, such as inflammation, apoptosis, proliferation, and autophagy [41]. Scientists suggest that RAGE plays important roles in several pathophysiologic processes such as cancer [42].

The aim of this study was to determine the possible involvement of STAT3, SIRT1, FGFR2, and RAGE gene polymorphisms in LSCC patients as to the best of our knowledge, all these four gene polymorphisms are studied for the first time in LSCC patients.

\section{Methods and Materials}

2.1. Ethics Statement. The study was approved by the Ethics Committee for Biomedical Research in Lithuanian University of Health Sciences (LUHS) (permission number is BE2-34). All subjects provided written informed consent in accordance with the Declaration of Helsinki (the World Medical Association Declaration of Helsinki on Ethical Principles for Medical Research Involving Human Subjects). The study was conducted in the Department of Otolaryngology of LUHS and in the Laboratory of Ophthalmology, Neuroscience Institute of LUHS.

2.2. Study Population. A total of 944 subjects were evaluated, which includes 144 patients with LSCC and 800 healthy controls (reference group) (Table 1).

The control group included healthy subjects with no complains related to laryngeal disorders (507 women and 293 men, aged from 19 to 90 years). A voluntary agreement to participate in this research study was obtained from each participant.

The LSCC group consisted of 135 males and 9 females, who underwent surgical treatment at the Department of Otorhinolaryngology and at the Oncological Hospital of LUHS. The age of the LSCC patients ranged from 30 to 86 years (median 63 years). The clinical diagnosis of laryngeal malignancy was based on patients' complaints, typical signs revealed on video laryngoscopy and direct microlaryngoscopy, and the data of neck CT scan or NMR. The pathohistological diagnosis of LSCCs was proved at the Department of Pathology of LUHS.

2.3. DNA Extraction, Genotyping, and Statistical Analysis. The methods used in our research were described in previous studies $[43,44]$.

\section{Results}

The analysis of Hardy-Weinberg equilibrium on 144 patients and 800 healthy subjects revealed that any SNPs did not deviate from Hardy-Weinberg equilibrium (data shown in Table 2).

The analysis of genotype and allele distribution was performed on all 944 subjects (Table 3). Our study results showed that genotypes (AA, AG, and GG) of rs1800625 in RAGE gene were distributed statistically significantly differently between patients and controls (61.1\%, 30.6\%, and $8.3 \%$ vs. $72.5 \%, 25.8 \%$, and $1.8 \%$, respectively; $p<0.001$ ) and allele $\mathrm{G}$ at rs 1800625 was more frequently observed in 
TABLe 1: Demographic characteristics of the study population.

\begin{tabular}{lccc}
\hline Characteristic & LSCC & Groups & \\
& $n=144$ & $n=800$ & $p$ value \\
\hline Male, $n(\%)$ & $135(93.8)$ & $293(36.6)$ & $<0.001^{* *}$ \\
Female, $n(\%)$ & $9(6.2)$ & $507(63.4)$ & \\
Age \pm SD & $62.63(0.794)$ & $50.84(0.523)$ & $<0.001^{* *}$ \\
Median & 63 & 53 & \\
\hline
\end{tabular}

** significant; LSCC: laryngeal squamous cell carcinoma.

TABLE 2: Analysis of allele frequencies and genotype distribution with Hardy-Weinberg equilibrium (HWE).

\begin{tabular}{llccc}
\hline SNP & \multicolumn{2}{c}{ Allele frequency } & $\begin{array}{c}\text { Genotype } \\
\text { distribution }\end{array}$ & $\begin{array}{c}\text { HWE } \\
p \text { value }\end{array}$ \\
rs12778366 & C (0.11) & T (0.89) & $16 / 177 / 751$ & 0.143 \\
\hline rs2981582 & A $(0.36)$ & G $(0.64)$ & $133 / 411 / 400$ & 0.100 \\
rs744166 & A $(0.42)$ & G $(0.58)$ & $183 / 431 / 330$ & 0.05 \\
rs1800625 & G (0.14) & A (0.86) & $16 / 225 / 611$ & 0.654 \\
\hline
\end{tabular}

SNP: single-nucleotide polymorphism.

the patient group than in controls $(23.6 \%$ vs. $14.6 \% ; p<0.001)$ (Table 3).

Binomial logistic regression analysis was performed to evaluate SNPs as the risk factors for LSCC development (Table 4).

Genetic risk models revealed statistically significant variables only in the analysis of rs1800625. Results showed an 8.4-fold increased risk of LSCC development under the codominant $(\mathrm{OR}=8.377,95 \% \mathrm{CI}: 2.880-24.368 ; p<0.001)$, a 1.7-fold increased risk under the dominant $(\mathrm{OR}=1.677$; 95\% CI: 1.112-2.529; $p=0.014)$, and a 7.6-fold increased risk under the recessive $(\mathrm{OR}=7.623$; 95\% CI: 2.643-21.989; $p<0.001)$ models as well as under the additive model which shows that each copy of allele G increases the risk of LSCC development by 1.8-fold (OR = 1.844; 95\% CI: 1.301-2.613; $p=0.001$ ) (Table 4). According to AIC, the best genetic models were codominant and recessive models which show G/G genotype to be associated with an increased risk of LSCC development as well as the additive model which shows $G$ allele association with LSCC development.

\section{Discussion}

We have chosen to investigate four genes SIRT1, FGFR2, STAT3, and RAGE which are known to be closely associated with different types of cancer and are related to pathogenetic processes [45-48].

It has been suggested that a significant increase of SIRT1 expression in hepatocellular carcinoma [23]; breast, prostate, ovarian, gastric, and colon cancers $[25,26,28,49,50]$; glioblastoma [51]; and lymphoma [52] might be associated with the development and invasion of tumors.

Few years ago, Noguchi et al. [53] investigated SIRT1 expression to clarify its biological behavior and identify its usefulness as a biomarker for head and neck squamous cell carcinoma (HNSCC). The study showed that $79.6 \%$ of STIR1 in HNSCC tissue and nearly all normal tissues were positively stained by immunohistochemical staining of SIRT1 with expression predominated in cases involving patients aged $>65$ years, lymph node negative, and early clinical stage cases. Thus, this analysis revealed that expression of STIR1 in HNSCC is an independent and good indicator of prognosis.

It was found that Rs12778366 polymorphism of SIRT1 gene is associated with breast cancer [54]. Findings of Rizk et al. revealed that SIRT1 rs12778366 TT genotypes were more frequent in CC and CT genotypes and were associated with histological grade of cancer and lymph node status. SIRT1 rs12778366 TT genotype also correlated with negative estrogen receptor and progesterone receptor statuses. The $\mathrm{T}$ allele frequency was higher in breast cancer patients than in normal subjects. However, in the current study, no differences in genotype (TT, TC, and CC) distribution were observed between the control and LSCC groups ( 80.6 vs. $73.6 \%, 17.6$ vs. $25.0 \%$, and 1.8 vs. $1.4 \%$, respectively; $p=0.111$ ).

Tyrosine kinase FGF receptor FGFR2 was found to be overexpressed in bladder [55] and lung cancer [56]. In addition, a study carried out by Zhang et al. [57] revealed that expression of FGFR2 correlated with the occurrence and development of LSCC. Their results showed that expression of FGFR2 from LSCC to para-carcinoma and normal laryngeal mucosa tissues is declined, with statistical significance $(H=11.4573, p=0.01)$. The quantitative expression of FGFR2 protein was relatively higher $(\mathrm{FI}=1.8776 \pm 0.1683)$ in LSCC than in para-carcinoma $(F I=1.1815 \pm 0.2710)$ and normal laryngeal mucosa $(\mathrm{FI}=1.0100 \pm 0.1341)$ tissues.

The importance of FGFR2 rs2981582 gene polymorphism was studied in breast [38, 58-66] and prostate cancer [67]. A study in Tunisian population reported that subjects with AA genotype of FGFR2 rs2981582 had increased risk of breast cancer [68]. Subsequently, Butt et al. [59] in their cohort study in Swedish population confirmed the association between AA genotypes of FGFR2 rs2981582 and increased breast cancer risk. In contrast, Chen et al. [38] in their study revealed that GA and AA genotypes of FGFR2 rs2981582 appear to be associated with lower mammographic density and reduced breast cancer risk. Environmental factors and racial/ethnic differences that vary among populations may affect the associations between SNPs and risk of breast cancer. It could be explained by modulating complex interactions between various genes.

FGFR is implicated in the development and progression of the majority of the cancers; therefore, the exact and known mechanisms could be developed to block FGFR activation in cancer cells in the next future $[69,70]$.

The current study also evaluates the importance of FGFR2 rs2981582 gene polymorphism in LSCC. All genotypes (GG, GA, and AA) were similar in the control and LSCC groups ( 42.1 vs. $43.8 \%, 43.9$ vs. $41.7 \%$, and 14.0 vs. $14.6 \%$, respectively; $p=0.886)$. This analysis revealed that there was no statistically significant difference between FGFR2 rs2981582 gene polymorphism in LSCC and that in the control groups. 
TABLE 3: Frequency of the genotypes of rs12778366, rs2981582, rs744166, and rs 1800625 polymorphisms in the LSCC and in the control groups.

\begin{tabular}{|c|c|c|c|c|}
\hline Gene marker & Genotype/allele & $\begin{array}{c}\text { Control } \\
n(\%) \\
(n=800) \\
\end{array}$ & $\begin{array}{c}\text { LSCC } \\
n(\%) \\
(n=144) \\
\end{array}$ & $p$ value \\
\hline \multirow{5}{*}{ SIRT1 rs12778366 } & $\mathrm{TT}$ & $645(80.6)$ & $106(73.6)$ & \multirow[t]{3}{*}{0.111} \\
\hline & TC & $141(17.6)$ & $36(25.0)$ & \\
\hline & $\mathrm{CC}$ & $14(1.8)$ & $2(1.4)$ & \\
\hline & $\mathrm{T}$ & $1431(89.4)$ & $248(86.1)$ & \multirow[t]{2}{*}{0.098} \\
\hline & $\mathrm{C}$ & $169(10.6)$ & $40(13.9)$ & \\
\hline \multirow{5}{*}{ FGFR2 rs2981582 } & GG & $337(42.1)$ & $63(43.8)$ & \multirow[t]{2}{*}{0.886} \\
\hline & GA & $351(43.9)$ & $60(41.7)$ & \\
\hline & AA & $112(14.0)$ & $21(14.6)$ & \multirow{3}{*}{0.865} \\
\hline & G & $1025(64.1)$ & $186(64.6)$ & \\
\hline & A & $575(35.9)$ & $102(35.4)$ & \\
\hline \multirow{5}{*}{ STAT3 rs744166 } & $\mathrm{AA}$ & $283(35.4)$ & $47(32.6)$ & \multirow[t]{3}{*}{0.818} \\
\hline & AG & $363(45.4)$ & $68(47.2)$ & \\
\hline & GG & $154(19.2)$ & $29(20.1)$ & \\
\hline & $\mathrm{A}$ & $929(58.1)$ & $162(56.3)$ & \multirow[t]{2}{*}{0.566} \\
\hline & G & $671(41.9)$ & $126(43.7)$ & \\
\hline \multirow{5}{*}{ RAGE rs1800625 } & AA & $580(72.5)$ & $88(61.1)$ & \multirow[t]{3}{*}{$<0.001$} \\
\hline & AG & $206(25.8)$ & $44(30.6)$ & \\
\hline & GG & $14(1.8)$ & $12(8.3)$ & \\
\hline & A & $1366(85.4)$ & $220(76.4)$ & \multirow[t]{2}{*}{$<0.001$} \\
\hline & G & $234(14.6)$ & $68(23.6)$ & \\
\hline
\end{tabular}

HWE: Hardy-Weinberg equilibrium; SIRT1: sirtuin 1 gene; FGFR2: fibroblast growth factor receptor 2 gene; STAT3: signal transducer and activator of transcription 3 gene; RAGE: advanced glycosylation end product receptor gene; LSCC: laryngeal squamous cell carcinoma. $p$ values indicated in bold are statistically significant.

Several reports described the influence of STAT3 in the tumor development of colorectal adenocarcinoma, hepatocellular carcinoma, multiple myeloma, glioblastoma, and prostate, head, and neck cancers [71-76]. In 2008, Liu et al. [77] performed a study to investigate the expression and activation of STAT3 in laryngeal carcinoma. The overexpression of STAT3 was determined in all samples of laryngeal squamous cell carcinoma. The mRNA levels of STAT3 were 2.1-fold higher in carcinoma tissue than in control mucosa, respectively. In addition, the protein levels of STAT3 and p-STAT3 were 1.6- and 4.5-fold higher in carcinoma tissue than in control mucosa. It shows that STAT3 is important in the development of LSCCs and represents a potential novel molecular target for therapy to improve survival of patients with LSCC. Several other studies $[78,79]$ were performed to determine the influence of the Janus-activated kinase (JAK)/STAT inhibitor AG490 on proliferation and apoptosis of Hep-2 human laryngeal cancer cells and to determine whether there was any inhibition by AG490 of the JAK/STAT3 signaling pathway. It was determined that AG490 inhibits significant proliferation, invasion, vasculogenic mimicry, and induced apoptosis of laryngeal carcinoma cells through downregulation of STAT3, suggesting a potential target for LSCC treatment.
A literature search for information on STAT3 rs744166 polymorphism has yielded few studies on gastric, colon, and lung cancer $[80,81,80,19]$. Yuan et al. [81] showed that rs744166 polymorphism of the STAT3 gene, along with environmental factors, might be associated with the development of gastric cancer. The TC genotype (adjusted OR $=0.60,95 \%$ $\mathrm{CI}=0.39-0.92$, and $p=0.020$ ) and CC genotype (adjusted $\mathrm{OR}=0.41,95 \% \mathrm{CI}=0.21-0.80$, and $p=0.009$ ) were associated with a decreased risk of gastric cancer comparing to the TT genotype. In addition, Rocha et al. [80] provided the evidence that STAT3 rs744166 G allele is an independent risk factor for gastric cancer. Moreover, Ryan et al. [82] found that rs744166 in STAT3 was associated with a colon cancer risk, while Jiang et al. [19] determined that carriers of STAT3 rs744166 have a significantly decreased risk of non-small-cell lung cancer. In the study reported here, association between STAT3 rs744166 and LSCC risk was not determined. Statistical analysis showed that genotypes (AA, AG, and GG) of rs744166 in STAT3 gene were not distributed significantly different between patients and controls $(32.6 \%, 47.2 \%$, and $20.1 \%$ vs. $35.4 \%, 45.4 \%$, and $19.2 \%$, respectively; $p=0.818$ ). The same statistical significance was observed comparing allele distribution in patients and controls (allele $\mathrm{A}$ at rs744166 in the patient group-56.3\%, in controls-58.1\%; $p=0.566)$. 
TABLE 4: Binomial logistic regression analysis of rs12778366, rs2981582, rs744166, and rs1800625 polymorphisms in the laryngeal squamous cell carcinoma and in the control groups.

\begin{tabular}{|c|c|c|c|c|}
\hline Model & Genotype & ${ }^{*} \mathrm{aOR}(95 \% \mathrm{CI})$ & $p$ & AIC \\
\hline \multicolumn{5}{|c|}{ SIRT1 rs12778366 } \\
\hline Codominant & $\begin{array}{l}\mathrm{T} / \mathrm{C} \\
\mathrm{C} / \mathrm{C}\end{array}$ & $\begin{array}{l}1.519(0.951-2.426) \\
1.307(0.241-7.095)\end{array}$ & $\begin{array}{l}0.080 \\
0.757\end{array}$ & 625.205 \\
\hline Dominant & $\mathrm{T} / \mathrm{C}+\mathrm{C} / \mathrm{C}$ & $1.506(0.953-2.380)$ & 0.080 & 623.235 \\
\hline Recessive & $\mathrm{C} / \mathrm{C}$ & $1.194(0.221-6.461)$ & 0.837 & 626.200 \\
\hline Overdominant & $\mathrm{T} / \mathrm{C}$ & $1.513(0.948-2.413)$ & 0.083 & 623.298 \\
\hline Additive & - & $1.421(0.937-2.155)$ & 0.098 & 624.571 \\
\hline \multicolumn{5}{|c|}{ FGFR2 rs2981582 } \\
\hline Codominant & $\begin{array}{l}\text { G/A } \\
\mathbf{A} / \mathbf{A}\end{array}$ & $\begin{array}{l}0.951(0.624-1.452) \\
0.947(0.525-1.705)\end{array}$ & $\begin{array}{l}0.818 \\
0.855\end{array}$ & 628.177 \\
\hline Dominant & $\mathrm{G} / \mathrm{A}+\mathrm{A} / \mathrm{A}$ & $0.950(0.641-1.408)$ & 0.799 & 626.177 \\
\hline Recessive & $\mathbf{A} / \mathbf{A}$ & $0.970(0.559-1.683)$ & 0.914 & 626.230 \\
\hline Overdominant & G/A & $0.965(0.650-1.433)$ & 0.859 & 626.210 \\
\hline Additive & - & $0.968(0.734-1.276)$ & 0.816 & 626.188 \\
\hline \multicolumn{5}{|l|}{ STAT3 rs744166 } \\
\hline Codominant & $\begin{array}{l}\mathrm{A} / \mathrm{G} \\
\mathrm{G} / \mathrm{G}\end{array}$ & $\begin{array}{l}1.216(0.783-1.887) \\
1.378(0.790-2.404)\end{array}$ & $\begin{array}{l}0.384 \\
0.259\end{array}$ & 626.801 \\
\hline Dominant & $\mathrm{A} / \mathrm{G}+\mathrm{G} / \mathrm{G}$ & $1.260(0.835-1.902)$ & 0.271 & 625.015 \\
\hline Recessive & G/G & $1.233(0.752-2.023)$ & 0.406 & 625.563 \\
\hline Overdominant & A/G & $1.088(0.736-1.608)$ & 0.672 & 626.063 \\
\hline Additive & - & $1.179(0.898-1.548)$ & 0.235 & 624.830 \\
\hline \multicolumn{5}{|c|}{ RAGE rs1800625 } \\
\hline Codominant & $\begin{array}{l}\mathrm{A} / \mathrm{G} \\
\mathrm{G} / \mathrm{G}\end{array}$ & $\begin{array}{c}1.371(0.887-2.120) \\
8.377(2.880-24.368)\end{array}$ & $\begin{array}{c}0.156 \\
<\mathbf{0 . 0 0 1}\end{array}$ & 611.143 \\
\hline Dominant & $\mathrm{A} / \mathrm{G}+\mathrm{G} / \mathrm{G}$ & $1.677(1.112-2.529)$ & 0.014 & 620.248 \\
\hline Recessive & $\mathrm{G} / \mathrm{G}$ & $7.623(2.643-21.989)$ & $<0.001$ & 611.128 \\
\hline Overdominant & $\mathrm{A} / \mathrm{G}$ & $1.223(0.796-1.877)$ & 0.358 & 625.406 \\
\hline Additive & - & $1.844(1.301-2.613)$ & 0.001 & 614.547 \\
\hline
\end{tabular}

*aOR: adjusted odds ratio by age and gender; CI: confidence interval; AIC: Akaike Information Criterion.

Ample studies have suggested several RAGE gene polymorphisms, alone or in combination with other factors, which are associated with the development or progression of various types of cancer-such as gastric, lung, colorectal, breast, cervical, and ovarian cancers [83-90]. Genetic variations in gene sequence have a potential to alter the function or of $R A G E$, leading to changes in its final bioavailability and, thus, the carcinogenesis [84].

A study conducted by Wang et al. [86] showed that expression of RAGE was reduced in tissues from human lung cancer patients. It should be noted that the polymorphisms of RAGE, in particular the $-429 \mathrm{~T} / \mathrm{C}$ (rs1800625) and 2184A/G (rs2070600) polymorphisms, were associated with the genesis and progression of lung cancer. The levels of serum sRAGE and tissue RAGE potentially could be an effective and convenient diagnostic biomarker for lung cancer, and the presence of $R A G E$ polymorphism may aid the diagnosis of lung cancer and the clinical assessment of prognosis.

$\mathrm{Su}$ et al. [84] study showed that RAGE rs1800625 is associated with the risk and/or progression of oral squamous cell carcinoma. Moreover, a study revealed that the
RAGE gene polymorphism rs1800625 not only conferred an increased risk of oral cancer but also was associated with late-stage and large-size tumors. This study also found that individuals who carry at least 1 polymorphic allele of rs1800625, smoke, and chew betel nuts are more susceptible to oral cancer.

Our study was the first to assess the association between RAGE rs1800625 and LSCC. It was found that the GG genotype was more frequent in the LSCC group compared with the healthy controls ( 8.3 vs. $1.8 \%$, respectively; $p<0.00$ ) and the AA genotype was less frequent in the LSCC group compared with healthy control group (61.1 vs. $72.5 \%$, respectively; $p<0.001$ ). Allele $\mathrm{G}$ at rs 1800625 was more frequently observed in the patient group than in controls $(23.6 \%$ vs. $14.6 \% ; p<0.001)$.

Moreover, RAGE rs1800625 analysis revealed that there were significant variables in the codominant $(\mathrm{OR}=8.377$; 95\% CI: 2.880-24.368; $p<0.001)$, recessive $(\mathrm{OR}=7.623$; 95\% CI: $2.643-21.989 ; p<0.001)$ and additive $(\mathrm{OR}=1.844$; 95\% CI: $1.301-2.613 ; p=0.001)$ models of the patients with LSCC and the control group. 


\section{Conclusions}

In conclusion, RAGE rs1800625 gene polymorphism might play a significant role in laryngeal squamous cell carcinoma development. To our knowledge, there are no reports on the association of RAGE gene polymorphism with LSCC, so its role as a biomarker for prognosis of LSCC development cannot yet be confirmed. For this reason, further studies are needed to explore and confirm this association.

\section{Data Availability}

The data used to support the findings of this study are available from the corresponding author upon request.

\section{Conflicts of Interest}

None of the authors has any proprietary interests or conflicts of interest related to this submission.

\section{References}

[1] J. Fernández-Mateos, R. Seijas-Tamayo, J. C. Adansa Klain et al., "Genetic susceptibility in head and neck squamous cell carcinoma in a Spanish population," Cancers, vol. 11, no. 4, p. 493, 2019.

[2] R. Takiar, S. K. Krishnan, and V. P. Shah, "A model approach to calculate cancer prevalence from 5 years survival data for selected cancer sites in India - part II," Asian Pacific Journal of Cancer Prevention, vol. 15, no. 14, pp. 5681-5684, 2014.

[3] K. Markou, A. Christoforidou, I. Karasmanis et al., "Laryngeal cancer: epidemiological data from Northern Greece and review of the literature," Hippokratia, vol. 17, no. 4, pp. 313318, 2013.

[4] J. Ferlay, E. Steliarova-Foucher, J. Lortet-Tieulent et al., "Cancer incidence and mortality patterns in Europe: estimates for 40 countries in 2012," European Journal of Cancer, vol. 49, no. 6, pp. 1374-1403, 2013.

[5] "GLOBOCAN 2018: Estimated Cancer Incidence, Mortality and Prevalence Worldwide in 2018," https://gco.iarc.fr/today/ data/factsheets/cancers/14-Larynx-fact-sheet.pdf.

[6] B. Lu, J. Li, Q. Gao, W. Yu, Q. Yang, and X. Li, "Laryngeal cancer risk and common single nucleotide polymorphisms in nucleotide excision repair pathway genes ERCC1, ERCC2, ERCC3, ERCC4, ERCC5 and XPA," Gene, vol. 542, no. 1, pp. 64-68, 2014.

[7] X. Li, J. Xu, X. Yang et al., "Association of single nucleotide polymorphisms of nucleotide excision repair genes with laryngeal cancer risk and interaction with cigarette smoking and alcohol drinking," Tumor Biology, vol. 35, no. 5, pp. 46594665, 2014.

[8] H. Romanowicz-Makowska, B. Smolarz, M. Gajęcka et al., "Polymorphism of the DNA repair genes RAD51 and XRCC2 in smoking- and drinking-related laryngeal cancer in a Polish population," Archives of Medical Science, vol. 6, no. 6, pp. 1065-1075, 2012.

[9] K. Kupisz, A. Stepulak, M. Zdunek, and J. Klatka, "Preliminary results of prognostic significance of proliferating cell nuclear antigen expression in advanced primary larynx carcinomas and lymph node metastases," Archives of Medical Science, vol. 1, no. 1, pp. 65-70, 2010.

[10] E. Pawlowska, K. Janik-Papis, M. Rydzanicz et al., "The Cys326 allele of the 8-oxoguanine DNA N-glycosylase 1 gene as a risk factor in smoking- and drinking-associated larynx cancer," The Tohoku Journal of Experimental Medicine, vol. 219, no. 4, pp. 269-275, 2009.

[11] S. Marur, G. D'Souza, W. H. Westra, and A. A. Forastiere, "HPV-associated head and neck cancer: a virus-related cancer epidemic," The Lancet Oncology, vol. 11, no. 8, pp. 781-789, 2010.

[12] J. Wang, X. Jin, H. Wang et al., "The -308G/A polymorphism of the tumor necrosis factor-alpha gene is associated with the risk of upper aerodigestive tract cancer: a meta-analysis," The Tohoku Journal of Experimental Medicine, vol. 229, no. 4, pp. 245-254, 2013.

[13] H. Huangfu, H. Pan, B. Wang, S. Wen, R. Han, and L. Li, "Association between UGT1A1 polymorphism and risk of laryngeal squamous cell carcinoma," International Journal of Environmental Research and Public Health, vol. 13, no. 1, p. 112, 2016.

[14] H. Yu, D. Pardoll, and R. Jove, "STATs in cancer inflammation and immunity: a leading role for STAT3," Nature Reviews Cancer, vol. 9, no. 11, pp. 798-809, 2009.

[15] J. Chen, J. Wang, L. Lin et al., "Inhibition of STAT3 signaling pathway by nitidine chloride suppressed the angiogenesis and growth of human gastric cancer," Molecular Cancer Therapeutics, vol. 11, no. 2, pp. 277-287, 2012.

[16] A. Sekikawa, H. Fukui, S. Fujii et al., "REG I $\alpha$ protein mediates an anti-apoptotic effect of STAT3 signaling in gastric cancer cells," Carcinogenesis, vol. 29, no. 1, pp. 76-83, 2008.

[17] N. Ito, M. Eto, E. Nakamura et al., "STAT3 polymorphism predicts interferon-alfa response in patients with metastatic renal cell carcinoma," Journal of Clinical Oncology, vol. 25, no. 19, pp. 2785-2791, 2007.

[18] S. M. Kim, O. J. Kwon, Y. K. Hong et al., "Activation of IL6R/JAK1/STAT3 signaling induces de novo resistance to irreversible EGFR inhibitors in non-small cell lung cancer with T790M resistance mutation," Molecular Cancer Therapeutics, vol. 11, no. 10, pp. 2254-2264, 2012.

[19] B. Jiang, Z. Z. Zhu, F. Liu et al., "STAT3 gene polymorphisms and susceptibility to non-small cell lung cancer," Genetics and Molecular Research, vol. 10, no. 3, pp. 1856-1865, 2011.

[20] L. Zhao, Q. Zhang, X. Luan, X. Huang, S. Zhao, and H. Zhao, "STAT3 and STAT5b polymorphism contributes to breast cancer risk and clinical outcomes," International Journal of Clinical and Experimental Pathology, vol. 8, no. 2, pp. 20332038, 2015.

[21] E. M. Kwon, C. A. Salinas, S. Kolb et al., "Genetic polymorphisms in inflammation pathway genes and prostate cancer risk," Cancer Epidemiology Biomarkers \& Prevention, vol. 20, no. 5, pp. 923-933, 2011.

[22] Y. Dong, T. Guo, M. Traurig et al., "SIRT1 is associated with a decrease in acute insulin secretion and a sex specific increase in risk for type 2 diabetes in Pima Indians," Molecular Genetics and Metabolism, vol. 104, no. 4, pp. 661-665, 2011.

[23] H.-C. Chen, Y.-M. Jeng, R.-H. Yuan, H.-C. Hsu, and Y.-L. Chen, "SIRT1 promotes tumorigenesis and resistance to chemotherapy in hepatocellular carcinoma and its expression predicts poor prognosis," Annals of Surgical Oncology, vol. 19, no. 6, pp. 2011-2019, 2012. 
[24] S. Maeda, D. Koya, S. I. Araki et al., “Association between single nucleotide polymorphisms within genes encoding sirtuin families and diabetic nephropathy in Japanese subjects with type 2 diabetes," Clinical and Experimental Nephrology, vol. 15, no. 3, pp. 381-390, 2011.

[25] J.-Y. Sung, R. Kim, J.-E. Kim, and J. Lee, "Balance between SIRT1 and DBC1 expression is lost in breast cancer," Cancer Science, vol. 101, no. 7, pp. 1738-1744, 2010.

[26] D. M. Huffman, W. E. Grizzle, M. M. Bamman et al., "SIRT1 is significantly elevated in mouse and human prostate cancer," Cancer Research, vol. 67, no. 14, pp. 6612-6618, 2007.

[27] C. A. Bradbury, F. L. Khanim, R. Hayden et al., "Histone deacetylases in acute myeloid leukaemia show a distinctive pattern of expression that changes selectively in response to deacetylase inhibitors," Leukemia, vol. 19, no. 10, pp. 1751-1759, 2005.

[28] W. Stünkel, B. K. Peh, Y. C. Tan et al., "Function of the SIRT1 protein deacetylase in cancer," Biotechnology Journal, vol. 2, no. 11, pp. 1360-1368, 2007.

[29] C.-S. Lim, "SIRT1: tumor promoter or tumor suppressor?," Medical Hypotheses, vol. 67, no. 2, pp. 341-344, 2006.

[30] R.-H. Wang, K. Sengupta, C. Li et al., "Impaired DNA damage response, genome instability, and tumorigenesis in SIRT1 mutant mice," Cancer Cell, vol. 14, no. 4, pp. 312-323, 2008.

[31] K. Li and J. Luo, "The role of SIRT1 in tumorigenesis," North American Journal of Medical Sciences, vol. 4, no. 2, pp. 104106, 2011.

[32] J. Wesche, K. Haglund, and E. M. Haugsten, "Fibroblast growth factors and their receptors in cancer," Biochemical Journal, vol. 437, no. 2, pp. 199-213, 2011.

[33] L. Claesson-Welsh, "Signal transduction by fibroblast growth factor receptors," Frontiers in Bioscience, vol. 4, no. 4, pp. D165-D177, 1999.

[34] V. P. Eswarakumar, I. Lax, and J. Schlessinger, "Cellular signaling by fibroblast growth factor receptors," Cytokine \& Growth Factor Reviews, vol. 16, no. 2, pp. 139-149, 2005.

[35] N. Turner and R. Grose, "Fibroblast growth factor signalling: from development to cancer," Nature Reviews Cancer, vol. 10, no. 2, pp. 116-129, 2010.

[36] P. Xia, B. Li, T. Geng et al., "FGFR2 gene polymorphisms are associated with breast cancer risk in the Han Chinese population," American Journal of Cancer Research, vol. 5, no. 5, pp. 1854-1861, 2015.

[37] S. Siddiqui, S. Chattopadhyay, M. S. Akhtar et al., "A study on genetic variants of fibroblast growth factor receptor 2 (FGFR2) and the risk of breast cancer from North India," PLOS ONE, vol. 9, no. 10, p. e110426, 2014.

[38] Y. Chen, C. Shi, and Q. Guo, "TNRC9 rs12443621 and FGFR2 rs2981582 polymorphisms and breast cancer risk," World Journal of Surgical Oncology, vol. 14, no. 1, 2016.

[39] H. Nan, A. A. Qureshi, D. J. Hunter, and J. Han, "Genetic variants in FGFR2 and FGFR4 genes and skin cancer risk in the Nurses' Health Study," BMC Cancer, vol. 9, no. 1, article 1506, p. 172, 2009.

[40] A. Bierhaus, P. M. Humpert, M. Morcos et al., "Understanding RAGE, the receptor for advanced glycation end products," Journal of Molecular Medicine, vol. 83, no. 11, pp. 876-886, 2005.

[41] J. Xie, J. D. Méndez, V. Méndez-Valenzuela, and M. M. Aguilar-Hernández, "Cellular signalling of the receptor for advanced glycation end products (RAGE)," Cellular Signalling, vol. 25, no. 11, pp. 2185-2197, 2013.

[42] S. Park, S.-J. Yoon, H.-J. Tae, and C. Y. Shim, "RAGE and cardiovascular disease," Frontiers in Bioscience, vol. 16, pp. 486-497, 2011.

[43] R. Liutkeviciene, A. Vilkeviciute, L. Kriauciuniene, and V. P. Deltuva, "SIRT1 rs12778366, FGFR2 rs2981582, STAT3 rs744166, LIPC rs10468017, rs493258 and LPL rs12678919 genotypes and haplotype evaluation in patients with agerelated macular degeneration," Gene, vol. 686, pp. 8-15, 2019.

[44] R. Liutkeviciene, A. Vilkeviciute, G. Streleckiene, L. Kriauciuniene, R. Chaleckis, and V. P. Deltuva, "Associations of cholesteryl ester transfer protein (CETP) gene variants with predisposition to age-related macular degeneration," Gene, vol. 636, pp. 30-35, 2017.

[45] J.-C. Luo, Y. L. Peng, T. S. Chen et al., "Clopidogrel inhibits angiogenesis of gastric ulcer healing via downregulation of vascular endothelial growth factor receptor 2," Journal of the Formosan Medical Association, vol. 115, no. 9, pp. 764-772, 2016.

[46] J. Lu, L. Zhang, X. Chen et al., "SIRT1 counteracted the activation of STAT3 and NF- $\kappa$ B to repress the gastric cancer growth," International Journal of Clinical and Experimental Medicine, vol. 7, no. 12, pp. 5050-5058, 2014.

[47] M. Bernier, R. K. Paul, A. Martin-Montalvo et al., "Negative regulation of STAT3 protein-mediated cellular respiration by SIRT1 protein," Journal of Biological Chemistry, vol. 286, no. 22, pp. 19270-19279, 2011.

[48] Y. Nie, D. M. Erion, Z. Yuan et al., "STAT3 inhibition of gluconeogenesis is downregulated by SirT1," Nature Cell Biology, vol. 11, no. 4, pp. 492-500, 2009.

[49] K. Y. Jang, K. S. Kim, S. H. Hwang et al., "Expression and prognostic significance of SIRT1 in ovarian epithelial tumours," Pathology, vol. 41, no. 4, pp. 366-371, 2009.

[50] E. J. Cha, S. J. Noh, K. S. Kwon et al., "Expression of DBC1 and SIRT1 is associated with poor prognosis of gastric carcinoma," Clinical Cancer Research, vol. 15, no. 13, pp. 44534459, 2009.

[51] G. Liu, X. Yuan, Z. Zeng et al., "Analysis of gene expression and chemoresistance of CD133+ cancer stem cells in glioblastoma," Molecular Cancer, vol. 5, no. 1, p. 67, 2006.

[52] K. Y. Jang, S. H. Hwang, K. S. Kwon et al., "SIRT1 expression is associated with poor prognosis of diffuse large B-cell lymphoma," The American Journal of Surgical Pathology, vol. 32, no. 10, pp. 1523-1531, 2008.

[53] A. Noguchi, X. Li, A. Kubota et al., "SIRT1 expression is associated with good prognosis for head and neck squamous cell carcinoma patients," Oral Surgery, Oral Medicine, Oral Pathology and Oral Radiology, vol. 115, no. 3, pp. 385-392, 2013.

[54] S. M. Rizk, N. N. Shahin, and O. G. Shaker, "Association between SIRT1 gene polymorphisms and breast cancer in Egyptians," PloS One, vol. 11, no. 3, p. e0151901, 2016.

[55] D. Marzioni, T. Lorenzi, R. Mazzucchelli et al., "Expression of basic fibroblast growth factor, its receptors and syndecans in bladder cancer," International Journal of Immunopathology and Pharmacology, vol. 22, no. 3, pp. 627-638, 2009.

[56] H. Davies, C. Hunter, R. Smith et al., "Somatic mutations of the protein kinase gene family in human lung cancer," Cancer Research, vol. 65, no. 17, pp. 7591-7595, 2005.

[57] Q. Zhang, R. Duan, J. Chang, Q. Qi, S. Zhao, and Department of Otolaryngology Head and Neck Surgery, Affiliated Hospital 
of Hebei University of Engineering, "Expression of FGFR2 in laryngeal carcinoma and the clinical meaning," Chinese Archives of Otolaryngology-Head and Neck Surgery, vol. 21, no. 12, 2014http://en.cnki.com.cn/Article_en/CJFDTotalEBYT201412005.htm.

[58] S. Bayraktar, P. A. Thompson, S. Y. Yoo et al., "The relationship between eight GWAS-identified single-nucleotide polymorphisms and primary breast cancer outcomes," The Oncologist, vol. 18, no. 5, pp. 493-500, 2013.

[59] S. Butt, S. Harlid, S. Borgquist et al., "Genetic predisposition, parity, age at first childbirth and risk for breast cancer," $B M C$ Research Notes, vol. 5, no. 1, p. 414, 2012.

[60] F. Cui, D. Wu, W. Wang, X. He, and M. Wang, "Variants of FGFR2 and their associations with breast cancer risk: a HUGE systematic review and meta-analysis," Breast Cancer Research and Treatment, vol. 155, no. 2, pp. 313-335, 2016.

[61] D. Campa, M. Barrdahl, M. M. Gaudet et al., "Genetic risk variants associated with in situ breast cancer," Breast Cancer Research, vol. 17, no. 1, p. 82, 2015.

[62] U. A. Boyarskikh, N. A. Zarubina, J. A. Biltueva et al., "Association of FGFR2 gene polymorphisms with the risk of breast cancer in population of West Siberia," European Journal of Human Genetics, vol. 17, no. 12, 2009.

[63] J. K. Ledwoń, E. E. Hennig, N. Maryan et al., "Common lowpenetrance risk variants associated with breast cancer in Polish women,” BMC Cancer, vol. 13, no. 1, p. 510, 2013.

[64] E. Murillo-Zamora, H. Moreno-Macías, E. Ziv et al., “Association between rs2981582 polymorphism in the FGFR2 gene and the risk of breast cancer in Mexican women," Archives of Medical Research, vol. 44, no. 6, pp. 459-466, 2013.

[65] L. Ottini, V. Silvestri, C. Saieva et al., "Association of lowpenetrance alleles with male breast cancer risk and clinicopathological characteristics: results from a multicenter study in Italy," Breast Cancer Research and Treatment, vol. 138, no. 3, pp. 861-868, 2013.

[66] L. Jara, P. Gonzalez-Hormazabal, K. Cerceño et al., "Genetic variants in FGFR2 and MAP3K1 are associated with the risk of familial and early-onset breast cancer in a SouthAmerican population," Breast Cancer Research and Treatment, vol. 137, no. 2, pp. 559-569, 2013.

[67] F. L. Miles, J.-Y. Rao, C. Eckhert, S.-C. Chang, A. Pantuck, and Z.-F. Zhang, "Associations of immunity-related single nucleotide polymorphisms with overall survival among prostate cancer patients," International Journal of Clinical and Experimental Medicine, vol. 8, no. 7, pp. 11470-11476, 2015.

[68] J. Shan, W. Mahfoudh, S. P. Dsouza et al., "Genome-Wide Association Studies (GWAS) breast cancer susceptibility loci in Arabs: susceptibility and prognostic implications in Tunisians," Breast Cancer Research and Treatment, vol. 135, no. 3, pp. 715-724, 2012.

[69] R. Porta, R. Borea, A. Coelho et al., "FGFR a promising druggable target in cancer: molecular biology and new drugs," Critical Reviews in Oncology/Hematology, vol. 113, pp. 256-267, 2017.

[70] A. E. Quatrale, L. Porcelli, N. Silvestris, G. Colucci, A. Angelo, and A. Azzariti, "EGFR tyrosine kinases inhibitors in cancer treatment: in vitro and in vivo evidence," Frontiers in Bioscience, vol. 16, no. 1, pp. 1962-1972, 2011.

[71] T. Kusaba, T. Nakayama, K. Yamazumi et al., "Expression of p-STAT3 in human colorectal adenocarcinoma and adenoma; correlation with clinicopathological factors," Journal of Clinical Pathology, vol. 58, no. 8, pp. 833-838, 2005.
[72] G. He and M. Karin, "NF- $\kappa$ B and STAT3 - key players in liver inflammation and cancer," Cell Research, vol. 21, no. 1, pp. 159-168, 2011.

[73] M. K. Pandey, B. Sung, and B. B. Aggarwal, "Betulinic acid suppresses STAT3 activation pathway through induction of protein tyrosine phosphatase SHP-1 in human multiple myeloma cells," International Journal of Cancer, vol. 127, no. 2, pp. 282-292, 2010.

[74] M. B. Gariboldi, R. Ravizza, and E. Monti, "The IGFR1 inhibitor NVP-AEW541 disrupts a pro-survival and pro-angiogenic IGF- STAT3-HIF1 pathway in human glioblastoma cells," Biochemical Pharmacology, vol. 80, no. 4, pp. 455-462, 2010.

[75] J. Shin, H. J. Lee, D. B. Jung et al., "Suppression of STAT3 and HIF-1 alpha mediates anti-angiogenic activity of betulinic acid in hypoxic PC-3 prostate cancer cells," Plos One, vol. 6, no. 6, article e21492, 2011.

[76] R. J. Leeman-Neill, S. E. Wheeler, S. V. Singh et al., "Guggulsterone enhances head and neck cancer therapies via inhibition of signal transducer and activator of transcription-3," Carcinogenesis, vol. 30, no. 11, pp. 1848-1856, 2009.

[77] B. Liu, Z. Ren, Y. Shi, C. Guan, Z. Pan, and Z. Zong, “Activation of signal transducers and activators of transcription 3 and overexpression of its target gene CyclinD1 in laryngeal carcinomas," The Laryngoscope, vol. 118, no. 11, pp. 19761980, 2008.

[78] H. Zhang, D. Zhang, X. Luan, G. Xie, and X. Pan, "Inhibition of the signal transducers and activators of transcription (STAT) 3 signalling pathway by AG490 in laryngeal carcinoma cells," Journal of International Medical Research, vol. 38, no. 5, pp. 1673-1681, 2010.

[79] A. Hu, J. J. Huang, X. J. Jin et al., "Curcumin suppresses invasiveness and vasculogenic mimicry of squamous cell carcinoma of the larynx through the inhibition of JAK-2/STAT-3 signaling pathway," American Journal of Cancer Research, vol. 5, no. 1, pp. 278-288, 2014.

[80] G. A. Rocha, A. M. C. Rocha, A. D. Gomes et al., "STAT3 polymorphism and Helicobacter pylori CagA strains with higher number of EPIYA-C segments independently increase the risk of gastric cancer," BMC Cancer, vol. 15, no. 1, p. 528, 2015.

[81] K. Yuan, H. Liu, L. Huang et al., "rs744166 Polymorphism of the STAT3 Gene Is Associated with Risk of Gastric Cancer in a Chinese Population," BioMed Research International, vol. 2014, Article ID 527918, 8 pages, 2014.

[82] B. M. Ryan, R. K. Wolff, N. Valeri et al., "An analysis of genetic factors related to risk of inflammatory bowel disease and colon cancer," Cancer Epidemiology, vol. 38, no. 5, pp. 583-590, 2014.

[83] H. WANG, Y. Li, W. Yu, L. Ma, X. Ji, and W. Xiao, "Expression of the receptor for advanced glycation end-products and frequency of polymorphism in lung cancer," Oncology Letters, vol. 10, no. 1, pp. 51-60, 2015.

[84] S. Su, M. Chien, C. Lin, M. Chen, and S. Yang, "RAGE gene polymorphism and environmental factor in the risk of oral cancer," Journal of Dental Research, vol. 94, no. 3, pp. 403411,2014

[85] S.-C. Su, M.-J. Hsieh, Y.-E. Chou, W.-L. Fan, C.-B. Yeh, and S.F. Yang, "Effects of RAGE gene polymorphisms on the risk and progression of hepatocellular carcinoma," Medicine, vol. 94, no. 34, p. e1396, 2015.

[86] D. Wang, T. Li, G. Ye et al., "Overexpression of the receptor for advanced glycation endproducts (RAGE) is associated with 
poor prognosis in gastric cancer," PLoS ONE, vol. 10, no. 4, article e0122697, 2015.

[87] P. Tesarová, M. Kalousová, M. Jáchymová, O. Mestek, L. Petruzelka, and T. Zima, "Receptor for advanced glycation end products (RAGE) - soluble form (sRAGE) and gene polymorphisms in patients with breast cancer," Cancer Investigation, vol. 25, no. 8, pp. 720-725, 2007.

[88] Q. Xu, F. Xue, B. Yuan, L. Zhang, J. Li, and Z. He, “The interaction between RAGE gene polymorphisms and HPV infection in determining the susceptibility of cervical cancer in a Chinese population," Cancer Biomarkers, vol. 11, no. 4, pp. 147-153, 2012.

[89] S. Zhang, X. Hou, S. Zi, Y. Wang, L. Chen, and B. Kong, "Polymorphisms of receptor for advanced glycation end products and risk of epithelial ovarian cancer in Chinese patients," Cellular Physiology and Biochemistry, vol. 31, no. 4-5, pp. 525$531,2013$.

[90] F. Qian, B.-1. Sun, W.-Y. Zhang, J. Ke, and J. Zhu, "Gly82Ser polymorphism of the receptor for advanced glycation endproduct (RAGE) potential high risk in patients with colorectal cancer," Tumor Biology, vol. 35, no. 4, pp. 3171-3175, 2014. 


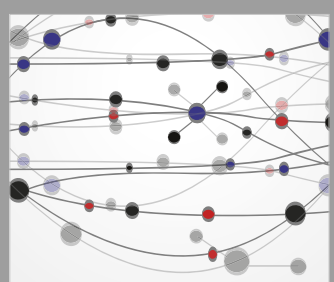

The Scientific World Journal
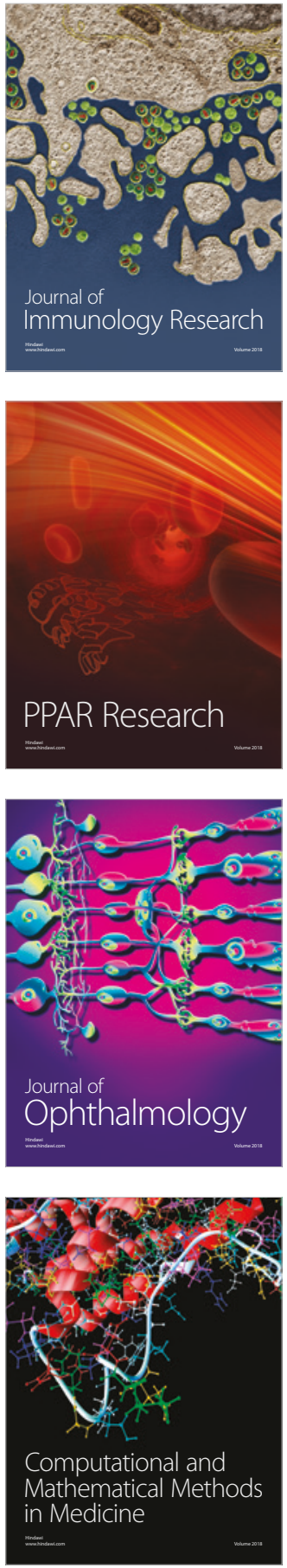

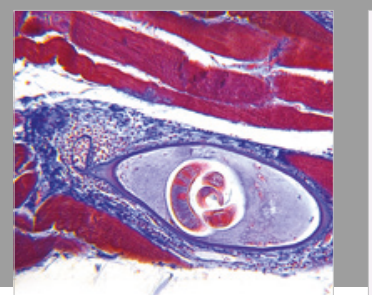

Gastroenterology Research and Practice

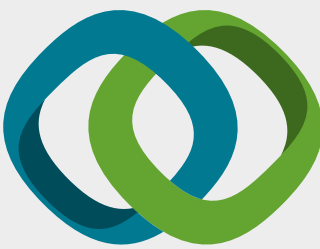

\section{Hindawi}

Submit your manuscripts at

www.hindawi.com
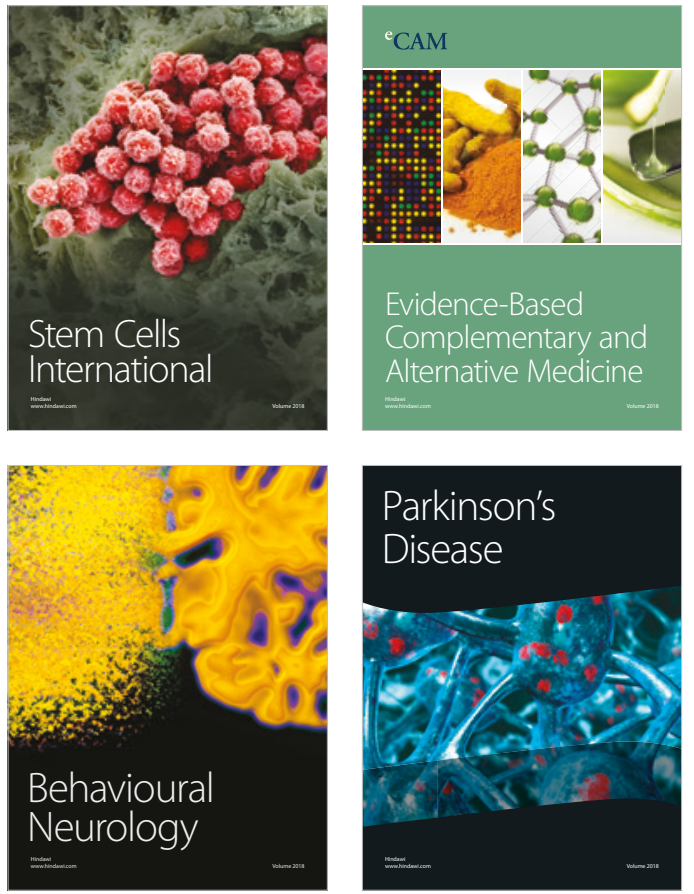

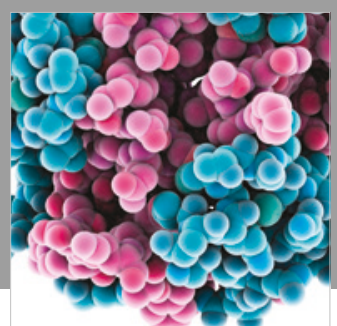

ournal of

Diabetes Research

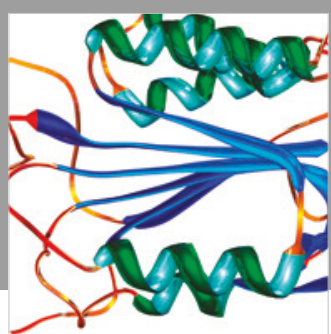

Disease Markers
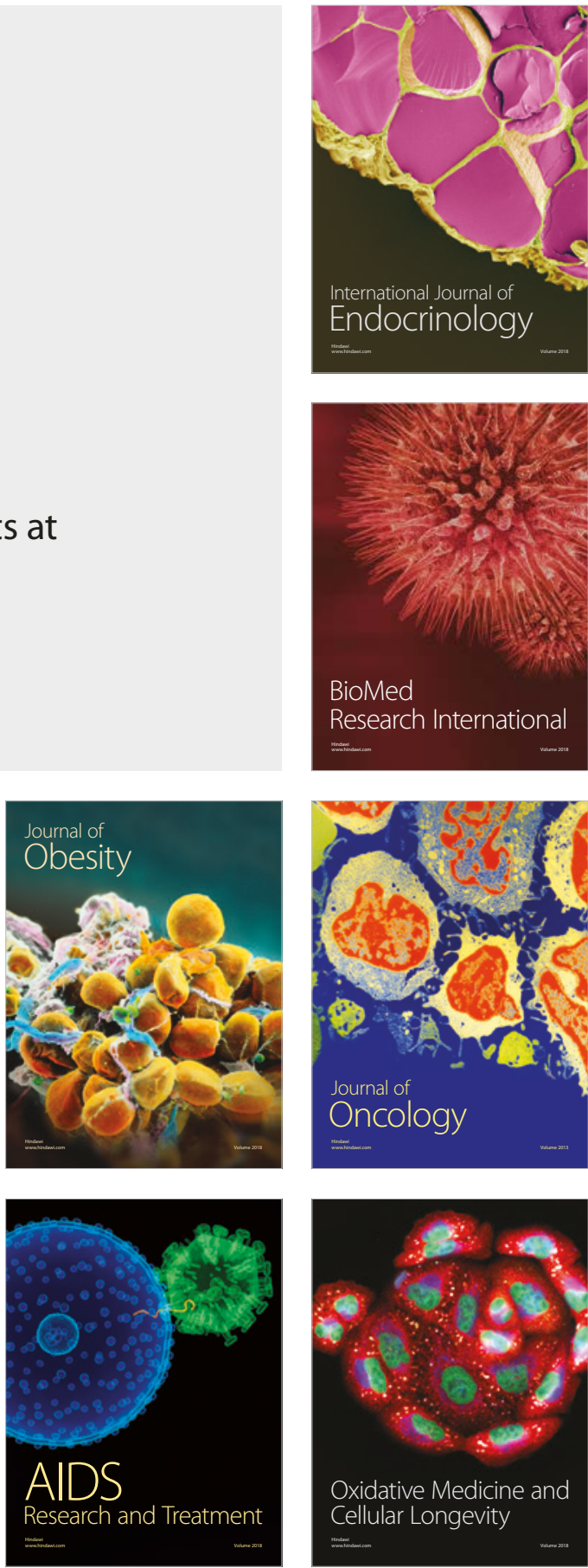